\title{
Um Estudo Empírico dos Determinantes da Adoção de Internet Banking entre Não Usuários Brasileiros
}

\section{An Empirical Study of the Determinants of Internet Banking Adoption among Brazilians Non-users}

José Mauro da Costa Hernandez* Doutor em Administração de Empresas pela EAESP-FGV. Professor do MPA/Uninove, São Paulo/SP, Brasil.

José Afonso Mazzon Doutor em Administração de Empresas pela FEA-USP. Professor Livre Docente na FEA-USP, São Paulo/SP, Brasil.

*Endereço: Rua Raul Pompéia, 905, apto. 154, São Paulo/SP, 05025-010. E-mail: jmhernandez@uninove.br 


\title{
ResUMo
}

Este estudo investiga os fatores determinantes da adoção de Internet Banking entre não usuários brasileiros. Para tanto propõe-se um modelo que reúne os constructos dos modelos mais conhecidos de adoção de novas tecnologias da literatura de marketing. $\mathrm{O}$ modelo foi testado com amostra de 292 pessoas e os resultados revelam que os efeitos de oito variáveis sobre a intenção de usar o Internet Banking são significativos. São elas compatibilidade com estilo de vida, normas subjetivas, auto-eficácia, imagem, vantagem relativa de segurança e privacidade, vantagem relativa de controle, testagem e suporte tecnológico. Por outro lado, os efeitos das características individuais incluídas no modelo não se mostram significativos. A maior contribuição do estudo é a proposta de um modelo abrangente, simples e facilmente implementável. O estudo conclui apontando algumas implicações gerenciais, limitações e sugestões para estudos futuros.

Palavras-chave: comportamento do consumidor; adoção de novas tecnologias; internet banking; bancos.

\begin{abstract}
This study investigates the determinants of Internet Banking adoption among Brazilians non-users. To accomplish this objective, the study proposes a model built with constructs gathered from the most known models of new technology adoption found in the marketing literature. The model was tested among a sample of 292 people and the results show that the effects of eight variables were significant in determining the intention to adopt Internet Banking. They are compatibility with lifestyle, subjective norm, self-efficacy, image, relative advantage of security and privacy, relative advantage of control, trialability, and technological support. By the other side, none of the individual characteristics included in the model were significant. The major contribution of the study is the proposal of a comprehensive, simple, and easily implementable model. The study concludes by pointing some managerial implications, limitations, and suggestions for future studies.
\end{abstract}

Key words: consumer behavior; new technology adoption; internet banking; banks. 


\section{INTRODUÇÃO}

Os anos 80 testemunharam profunda mudança nos canais de distribuição de serviços da indústria bancária em direção aos canais de auto-atendimento. Pressionados por custos crescentes e por consumidores cada vez mais exigentes, para manter sua lucratividade e se diferenciar dos concorrentes, os bancos se viram obrigados a investir em novos canais de atendimento. Enquanto os terminais de auto-atendimento foram o motor do desenvolvimento desse novo formato de distribuição de serviços na década de 80 , o rápido desenvolvimento da Internet a partir de meados da década de 90 foi o elemento impulsionador de um novo canal de serviços bancários, o Internet Banking (Diniz, 2004).

No Brasil, as taxas de crescimento do Internet Banking (daqui por diante também referenciado por IB) nos últimos anos têm acompanhado de perto o desenvolvimento da própria Internet. Segundo dados da Federação Brasileira de Bancos [FEBRABAN] (2007a), o número de contas correntes cadastradas em IB saltou de 8,8 milhões em 2001 para 27,3 milhões em 2006, um crescimento de $210 \%$ em apenas 5 anos. Embora esta taxa de crescimento seja bastante expressiva, uma análise mais detalhada destes números revela que ainda existe grande potencial de crescimento para o IB. Considerando que no Brasil há 102,6 milhões de contas bancárias (FEBRABAN, 2007a), o número de contas cadastradas nos sistemas de IB dos bancos brasileiros representa pouco mais de $25 \%$ do total.

Ao se contrastar o desenvolvimento recente do Internet Banking e as suas perspectivas no Brasil com o fato de que, apenas em 2006, os bancos brasileiros investiram 5,3 bilhões de reais em tecnologia da informação (FEBRABAN, 2007b), parte dos quais em desenvolvimento de tecnologias de acesso remoto como o IB, é importante investigar os fatores que impedem as pessoas de movimentarem suas contas pela Internet. Na literatura de marketing, este tema geralmente é tratado sobre o tema de adoção de novas tecnologias (Davis, 1989; Rogers, 1983).

A revisão da literatura recente sobre marketing na indústria bancária revela que vários acadêmicos já se debruçaram sobre o processo de adoção do Internet Banking. Entretanto a utilização de diversos modelos teóricos e de ampla variedade de metodologias de coleta e análise de dados tornam difícil a comparação entre os diversos estudos e dificultam a integração dos seus resultados. Também se observa que estes acadêmicos têm demonstrado muito mais preocupação em propor novos constructos que expliquem a adoção de 
novas tecnologias do que em replicar os resultados dos poucos modelos teóricos que já se mostraram mais significativos.

Por outro lado, analisando-se a literatura acadêmica brasileira, observa-se que, apesar da sua relevância para a indústria bancária, a adoção de Internet Banking tem sido pouco investigada no Brasil (duas exceções são Costa, 2002; Müller, 2001). Portanto, o objetivo deste estudo é propor e testar um modelo que permita identificar os fatores que influenciam a adoção do IB no Brasil entre não usuários de IB. A justificativa para este objetivo é clara e imediata: não adianta os bancos gastarem fortunas em desenvolvimento de tecnologias de acesso remoto como o Internet Banking, se as pessoas não estão dispostas a utilizá-las. Identificar os fatores que facilitam ou dificultam a adoção do Internet Banking permitirá à indústria bancária desenvolver estratégias que aumentem a probabilidade de que seus clientes venham a adotar esta tecnologia.

Tendo em vista especialmente a sua aplicação pela indústria bancária, o objetivo deste estudo deve ser alcançado por meio do desenvolvimento de um modelo teórico abrangente e relativamente simples de ser colocado em prática.

Considerando o objetivo explicitado acima, este estudo está estruturado em 5 seções. Na primeira seção é revista a literatura sobre adoção de novas tecnologias e, especialmente, a adoção de Internet Banking. Esta seção conclui-se com a proposta de um modelo de adoção de Internet Banking que reúne os constructos dos principais modelos de adoção de novas tecnologias e que atende aos requisitos estabelecidos: abrangência e simplicidade. Na segunda seção descrevem-se os procedimentos utilizados para coletar e analisar os dados para teste do modelo. $\mathrm{Na}$ terceira seção são apresentados os resultados obtidos com o teste do modelo e na quarta seção discutem-se estes resultados. Para finalizar o estudo, a quinta seção apresenta as implicações gerenciais e as conclusões.

\section{REVISÃo dA Literatura}

\section{Adoção de Novas Tecnologias}

Várias perspectivas teóricas concorrentes têm sido oferecidas para se chegar aos determinantes da aceitação e utilização de uma nova tecnologia de informação (Venkatesh, Morris, Davis, \& Davis, 2003). Uma das linhas desta área concentrase nos determinantes da aceitação individual de novas tecnologias, utilizando a intenção comportamental ou o próprio comportamento como variáveis dependentes (Davis, 1989; Davis, Bagozzi, \& Warshaw, 1989). A maior parte desses modelos 
está fundamentada na Teoria da Ação Racional [TRA] (Fishbein \& Ajzen, 1975) e na Teoria do Comportamento Planejado [TPB] (Ajzen, 1985) e, portanto, os determinantes da adoção são definidos em termos de crenças, atitudes, normas subjetivas ou percepções sobre o controle do comportamento.

Uma segunda linha de pesquisas tem examinado a adoção de novas tecnologias de informação sob a perspectiva da Teoria de Difusão de Inovações (Rogers, 1983; Tornatzky \& Klein, 1982). Nesta linha de estudos os determinantes da adoção são definidos em função das características da nova tecnologia.

Esforços mais recentes (Taylor \& Todd, 1995) têm buscado integrar estas duas linhas de pesquisa ao propor modelos que considerem tanto o processo mental de adoção quanto as características da inovação tecnológica.

\section{Teoria da Difusão de Inovações (IDT)}

A Teoria da Difusão de Inovações (IDT, pela sigla em inglês de Innovation Diffusion Theory) tem sido utilizada desde os anos 60 para explicar o processo de adoção de inovações. Após ampla revisão de estudos das inovações, Rogers (1983) identificou cinco atributos de uma inovação que consistentemente se mostraram determinantes da sua taxa de difusão: vantagem relativa (do inglês relative advantage), compatibilidade (do inglês compatibility), complexidade (do inglês complexity), observabilidade (do inglês observability) e testagem (do inglês trialability).

Vantagem relativa pode ser definida como o grau em que uma inovação é percebida como superior às alternativas existentes. Compatibilidade, por sua vez, corresponde ao grau de consistência entre a inovação e os valores, necessidades e experiências dos usuários. Já complexidade se refere ao grau em que uma inovação é percebida como difícil de ser compreendida ou utilizada pelos seus usuários, enquanto observabilidade refere-se ao grau em que se possa observar, imaginar ou descrever os benefícios e atributos de uma inovação. Finalmente, testagem se refere ao grau em que uma inovação possa ser experimentada antes da sua adoção efetiva.

A hipótese é que quanto maior a percepção sobre a vantagem relativa, compatibilidade, observalidade e testagem de uma inovação, maior a probabilidade de que um indivíduo venha a adotá-la. Por outro lado, quanto maior a complexidade percebida de uma inovação, menor esta probabilidade.

Com o objetivo de desenvolver um instrumento para estudar a adoção inicial e a difusão de inovações de tecnologias de informação dentro das organizações, Moore e Benbasat (1991) tomaram como base as cinco características 
originalmente propostas por Rogers (1983) e adicionaram dois constructos. O primeiro constructo adicionado por Moore e Benbasat ao seu instrumento foi imagem, definida como o "grau em que o uso de uma inovação é percebido como capaz de melhorar a imagem ou o status de um indivíduo dentro de um sistema social" (p. 195). Segundo os autores, o racional para a inclusão deste construto ao modelo é que a imagem se mostrou importante determinante na adoção de novas tecnologias em estudos anteriores (Tornatzky \& Klein, 1982). Assim, por hipótese, quanto mais o indivíduo percebe que o seu status perante o grupo aumenta, caso ele adote a inovação, maior a sua intenção de adotar a inovação.

O segundo construto adicionado ao instrumento de mensuração por Moore e Benbasat (1991) foi o voluntariado na utilização, definido como "o grau no qual o uso de uma inovação é percebido como sendo voluntário ou de livre escolha" (p. 195). O racional para incluir este construto é que, ao se examinar uma inovação, deve-se considerar se os indivíduos são livres para adotar ou rejeitar uma inovação. Por hipótese, quanto menor a pressão para que um indivíduo adote uma nova tecnologia, maior a probabilidade de que ele venha a adotá-la.

Durante o refinamento de sua escala, Moore e Benbasat dividiram o construto observabilidade em dois outros: demonstrabilidade de resultados e visibilidade. $\mathrm{O}$ primeiro, demonstrabilidade de resultados, concentra-se sobre a tangibilidade dos resultados que a utilização de uma inovação proporciona, incluindo-se aí tanto o grau em que uma inovação pode ser observada antes de ser adotada quanto a sua capacidade de comunicar aos potenciais adotantes as características e atributos da inovação. O segundo construto, visibilidade, concentra-se apenas sobre o grau em que os resultados de uma inovação são visíveis aos potenciais adotantes. O efeito destes dois constructos sobre a intenção de adoção é o mesmo do construto observabilidade.

Moore e Benbasat enfatizam que o instrumento desenvolvido por eles procura medir não as características primárias da inovação em si mas a percepção dos indivíduos sobre as características da inovação. O racional por trás desta decisão é que o comportamento dos potenciais adotantes pode ser explicado pelo grau em que eles são capazes de perceber as características de uma inovação, independentemente das características reais da inovação. Uma vez que diferentes indivíduos podem perceber, de maneiras distintas, as características primárias de uma inovação, seus comportamentos podem diferir em função destas percepções.

\section{Teoria da Ação Racional (TRA)}

A Teoria da Ação Racional (TRA, pela sigla em inglês de Theory of Reasoned Action) foi proposta por Fishbein e Ajzen (1975) e é provavelmente uma das teorias 
mais influentes na explicação do comportamento humano (Venkatesh et al., 2003). De maneira simplificada, de acordo com esta teoria a intenção comportamental pode ser explicada pela atitude em relação ao comportamento e pela norma subjetiva. A atitude em relação ao comportamento é definida como "os sentimentos positivos ou negativos de um indivíduo sobre a adoção de um determinado comportamento" (Fishbein \& Ajzen, 1975, p. 216), enquanto a norma subjetiva pode ser definida como "a percepção de um indivíduo de que a maioria das pessoas que lhe são importantes acredita que ele deveria ou não se comportar de uma determinada maneira" (Fishbein \& Ajzen, 1975, p. 302). A atitude em relação ao comportamento, por sua vez, pode ser explicada pelas crenças salientes sobre o comportamento.

\section{Modelo de Aceitação de Tecnologias (TAM)}

De acordo com Davis et al. (1989), o Modelo de Aceitação de Tecnologia (TAM, pela sigla em inglês de Technology Acceptance Model) foi proposto originalmente por Davis (1986) para prever a aceitação e utilização de novas tecnologias de informação (softwares e sistemas de informação) dentro das organizações. O modelo é derivado do TRA e em sua versão final é bastante parcimonioso.

A intenção comportamental pode ser explicada pela atitude em relação à utilização do sistema e pela utilidade percebida do sistema. A atitude em relação à utilização do sistema, por sua vez, pode ser explicada tanto pela utilidade percebida do sistema quanto pela facilidade percebida de utilizar o sistema. A utilidade percebida foi definida por Davis (1989) como "o grau no qual uma pessoa acredita que a utilização de um determinado sistema pode contribuir para a melhoria da sua performance no trabalho" (p. 320). A melhoria da performance poderia ser atingida, por exemplo, quando se leva menos tempo para cumprir uma tarefa ou para produzir produtos de maior qualidade. Ainda para Davis (1989), a facilidade percebida de utilizar relaciona-se ao "grau no qual uma pessoa acredita que utilizar um determinado sistema estaria livre de esforço" (p. 320). Por hipótese, quanto maior a utilidade percebida e a facilidade percebida de utilizar, melhor a atitude do indivíduo em relação à inovação e maior a sua intenção de adotar a inovação.

Mais tarde, Venkatesh e Davis (2000), com base na Teoria da Ação Racional, acrescentaram ao TAM o construto norma subjetiva, modelo que ficou conhecido como TAM2. Por hipótese, quanto maior a influência dos pares sobre um indivíduo, maior a sua intenção em adotar a inovação.

\section{Teoria do Comportamento Planejado (TPB)}

A Teoria do Comportamento Planejado (TPB, pela sigla em inglês Theory of Planned Behavior) foi proposta por Ajzen (1985) como extensão da Teoria da 
Ação Racional (Fishbein \& Ajzen, 1975) para situações em que os indivíduos não têm controle completo sobre o seu comportamento. Basicamente, o TPB acrescenta um condicionante da intenção comportamental e da atitude em relação ao comportamento, que é o controle comportamental percebido. O controle comportamental percebido reflete as percepções do indivíduo quanto aos limites internos ou externos ao comportar-se, podendo ser definido mais formalmente como a facilidade ou dificuldade percebida por um indivíduo em se comportar de determinada maneira (Ajzen, 1985).

No TPB, o comportamento é função da intenção comportamental e do controle comportamental percebido. A intenção comportamental, por sua vez, é influenciada pela atitude em relação ao comportar-se pela norma subjetiva e pelo controle comportamental percebido. Cada um dos determinantes da intenção (atitude, norma subjetiva e controle comportamental percebido) é determinado pela estrutura de crenças subjacentes, referenciadas por crenças atitudinais, crenças normativas e crenças de controle, associadas à atitude, norma subjetiva e controle comportamental percebido, respectivamente.

\section{Teoria do Comportamento Planejado Decomposto (DTPB)}

No contexto de tecnologia de informação, Taylor e Todd (1995) propuseram um modelo chamado Teoria do Comportamento Planejado Decomposto (DTPB, pela sigla em inglês de Decomposed Theory of Planned Behavior), unindo conceitos das duas linhas de pesquisa (IDT e TPB). O DTPB decompõe as crenças atitudinais, normativas e de controle em constructos multidimensionais.

Segundo seus proponentes, o TPB decomposto tem diversas vantagens. Em primeiro lugar, os autores argumentam que é improvável que estruturas de crenças monolíticas que representem uma variedade de dimensões estejam consistentemente relacionadas com os antecedentes da intenção e, ao serem decompostas estas crenças, é provável que os relacionamentos se tornem mais claros e mais facilmente compreensíveis. Esta decomposição também pode proporcionar um conjunto estável de crenças que podem ser aplicadas a um conjunto variado de situações. Finalmente, o modelo se torna gerencialmente mais relevante, à medida que permite a identificação de fatores específicos que determinam a adoção e a utilização de nova tecnologia (Taylor \& Todd, 1995).

Desta forma, as crenças atitudinais são decompostas em três constructos: utilidade percebida, facilidade de utilização e compatibilidade. A utilidade percebida, derivada do TAM, é análoga ao constructo vantagem relativa do IDT e ambos têm sido operacionalizados de forma similar. Da mesma forma, a facilidade de 
utilização, também derivada do TAM, é similar ao constructo complexidade do IDT, embora no sentido contrário. Finalmente, compatibilidade é diretamente derivada do IDT.

Segundo Taylor e Todd (1995), as crenças normativas estão relacionadas por sua vez à divergência de opiniões entre os grupos de referência. Num ambiente organizacional, os três principais grupos de referência são os pares, os superiores e os subordinados, sendo que cada um deles pode ter opiniões divergentes sobre a adoção e utilização de uma nova tecnologia de informação. Desta forma, as crenças normativas são decompostas de acordo com o grupo de referência.

Finalmente, as crenças de controle são decompostas em dois grupos: o primeiro grupo compreende a noção interna de auto-eficácia e o segundo grupo compreende as limitações de recursos externos ou as condições facilitadoras. A auto-eficácia está relacionada à habilidade percebida de utilizar nova tecnologia. Em relação à utilização de uma tecnologia de informação, as condições facilitadoras referemse aos recursos físicos (tempo e dinheiro) e aos recursos tecnológicos. Por hipótese, quanto maior a percepção de auto-eficácia na utilização de nova tecnologia e quanto maior a percepção sobre a existência de condições facilitadoras, maior a intenção de adotar a inovação.

\section{Adoção de Internet Banking}

A literatura sobre tecnologias bancárias desenvolveu-se principalmente a partir do início da década de 90 com o surgimento de novas tecnologias que facilitaram o acesso remoto aos bancos. Inovações como o banco por telefone, o caixa automático, a crescente utilização dos cartões de débito e o acesso ao banco por meio de softwares proprietários, instalados em microcomputadores, despertaram o interesse de acadêmicos e praticantes. Esta literatura concentrou-se principalmente em quatro áreas: os novos serviços dos bancos de varejo, os canais de distribuição destes serviços, a percepção de bancos e banqueiros sobre as novas tecnologias bancárias e a percepção dos clientes sobre adoção destas tecnologias (Arkinci, Aksoy, \& Atilgan, 2004). Nesta última linha de estudos, os primeiros trabalhos concentraram-se em analisar a percepção do consumidor sobre novas tecnologias bancárias, como banco direto, banco por telefone e banco em casa (por exemplo, Howcroft, Hamilton, \& Hewer, 2002; Liao, Shao, Wang, $\&$ Chen, 1999).

No final da década de 90, o interesse se voltou para o Internet Banking e a sua adoção. Com base numa revisão dos artigos publicados sobre o assunto nos últimos 10 anos, pode-se dividir os estudos sobre adoção de IB em duas áreas: estudos descritivos e estudos relacionais. Os estudos descritivos se concentraram 
em identificar as características dos adotantes, suas reações e atitudes sobre a adoção do IB, barreiras à adoção do IB ou atributos do IB que o tornariam mais atrativo aos potenciais adotantes (por exemplo, Arkinci et al., 2004; Lee, Kwon, \& Schumann, 2005; Sathye, 1999).

Já o segundo grupo de estudos tem por objetivo exclusivo identificar as variáveis que influenciam a adoção do IB, utilizando os modelos de adoção de novas tecnologias mencionados anteriormente (IDT, TRA, TAM, TAM2, TPB e DTPB). A Tabela 1 apresenta o resultado desta revisão, apontando as principais características desse grupo de estudos.

O que se observa por meio da análise da Tabela 1 é que, em geral, os autores de estudos anteriores sobre adoção de IB incorporaram variáveis explicativas de um ou dois dos modelos tradicionais de adoção de tecnologia e adicionaram outras variáveis que poderiam aumentar a capacidade de explicação destes modelos teóricos. Entretanto observou-se que a adição de novas variáveis não aumentou sensivelmente a capacidade de explicação destes modelos, provavelmente pelo efeito de multicolinearidade com as variáveis existentes nos modelos originais.

Este estudo propõe-se investigar a adoção do IB, utilizando-se um modelo que reúne apenas os constructos de alguns dos modelos mais tradicionais e que já foram extensivamente testados. Este modelo teórico compreende quatro conjuntos de variáveis independentes:

- Do IDT e TAM foram incorporadas as características da inovação que influenciam a sua adoção. Mais especificamente, foram incorporadas as percepções sobre as características sugeridas por Moore e Benbasat (1991), isto é: vantagem relativa, visibilidade, demonstrabilidade de resultados, compatibilidade, complexidade, testagem e imagem. Como a adoção do IB tem natureza de adoção voluntária, o construto voluntariado foi excluído do modelo.

- Do DTPB foi incorporada a idéia de decomposição das crenças.

. Do TAM2 foram incorporadas as normas subjetivas.

- Do DTPB foi incorporado o controle comportamental percebido. Seguindo Tan e Teo (2000), as condições facilitadoras foram decompostas em suporte tecnológico e suporte governamental.

\section{- Características individuais}

Algumas características individuais foram incluídas no modelo, porque se mostraram relevantes em estudos anteriores sobre adoção do IB (Chang, 2003; Jaruwachirathanakul \& Fink, 2005; Lee et al., 2005). Além disto, segundo dados 
do Instituto Brasileiro de Opinião Pública e Estatística [IBOPE] (2006a, 2006b), os usuários brasileiros de Internet são mais jovens (64\% têm até 35 anos) e possuem renda superior aos não usuários. Por exemplo, enquanto $83 \%$ dos brasileiros de classe A utilizam a Internet, apenas $11 \%$ dos brasileiros das classes D/E a utilizam. Portanto é possível propor, com base em evidências anteriores, que indivíduos mais jovens, com maior escolaridade, com maior renda e que pertençam ao sexo masculino tenham maior intenção de usar o IB.

Ainda em relação às variáveis individuais, estudos anteriores identificaram que a possibilidade de acesso do indivíduo à tecnologia aumenta a probabilidade de que ele venha a adotá-la (Chau \& Lai, 2003; Karahanna \& Straub, 1999). Portanto é possível propor com base nestes resultados, que pessoas que possuam computador em suas residências ou que já utilizem a Internet, mesmo que fora de suas residências, tenham maior probabilidade de vir a adotar o Internet Banking.

\section{Tabela 1: Revisão Bibliográfica de Estudos Relacionais sobre Adoção de Internet Banking}

\begin{tabular}{|c|c|c|c|c|}
\hline Estudo & $\begin{array}{c}\text { Variáveis } \\
\text { Dependentes }\end{array}$ & Variáveis Independentes & $\begin{array}{l}\text { Teoria de } \\
\text { Suporte }\end{array}$ & País \\
\hline $\begin{array}{l}\text { Ndubisi e Sinti } \\
\text { (2006) }\end{array}$ & $\begin{array}{l}\text { Intenção } \\
\text { Usar IB }\end{array}$ & $\begin{array}{l}\text { Importância do IB Para as Necessidades do Cliente; } \\
\text { Compatibilidade; Complexidade; Testagem; Risco; Características } \\
\text { do Design do Site (hedônico vs. Utilitário) }\end{array}$ & IDT & Malásia \\
\hline $\begin{array}{l}\text { Shih e Fang } \\
(2006)\end{array}$ & $\begin{array}{l}\text { Intenção } \\
\text { Usar IB }\end{array}$ & $\begin{array}{l}\text { Atitude em Relação ao IB; Norma Subjetiva; Qualidade da Rede } \\
\text { (Qualidade da Informação; Velocidade da Transação; Segurança) }\end{array}$ & TRA & Taiwan \\
\hline $\begin{array}{l}\text { Lee } \text { et al. } \\
(2005)\end{array}$ & \begin{tabular}{|lr} 
Intenção & de \\
Usar IB; & Uso \\
Atual de IB &
\end{tabular} & $\begin{array}{l}\text { Importância Percebida de IB; Risco Percebido; Compatibilidade } \\
\text { com Serviços Existentes; Compatibilidade com a Internet }\end{array}$ & IDT & USA \\
\hline \begin{tabular}{|l|} 
Eriksson, \\
Kerom e \\
Nilsson (2005) \\
\end{tabular} & Uso Atual de IB & $\begin{array}{l}\text { Utilidade Percebida; Facilidade Percebida de Utilização; Confiança } \\
\text { no IB }\end{array}$ & TAM & Estônia \\
\hline $\begin{array}{l}\text { Brown, } \\
\text { Hoppe, } \\
\text { Mugera e } \\
\text { Newmann } \\
(2004)\end{array}$ & $\begin{array}{l}\text { Intenção } \\
\text { Usar IB }\end{array}$ & $\begin{array}{l}\text { Vantagem Relativa; Compatibilidade; Necessidades Bancárias; } \\
\text { Experiência com Internet; Complexidade; Testagem; Norma } \\
\text { Subjetiva; Risco Percebido; Auto-Eficácia; Suporte Tecnológico; } \\
\text { Suporte Governamental }\end{array}$ & $\begin{array}{l}\text { TPB } \\
\text { IDT }\end{array}$ & $\begin{array}{c}\text { África do } \\
\text { Sul }\end{array}$ \\
\hline $\begin{array}{l}\text { Chan e Lu } \\
(2004)\end{array}$ & \begin{tabular}{l|} 
Intenção \\
Usar \\
IB/Continuar \\
Usando IB
\end{tabular} & $\begin{array}{l}\text { Risco Percebido, Auto-eficácia com Computadores, Norma } \\
\text { Subjetiva, Imagem; Facilidade Percebida de Utilizar; Utilidade } \\
\text { Percebida; Capacidade de Demonstrar Resultados }\end{array}$ & \begin{tabular}{|c|} 
TAM 2 \\
Teoria \\
Cognitiva \\
Social; TPB
\end{tabular} & $\begin{array}{l}\text { Hong } \\
\text { Kong }\end{array}$ \\
\hline $\begin{array}{l}\text { Shih e Fang } \\
(2004)\end{array}$ & $\begin{array}{l}\text { Intenção } \\
\text { Usar IB; } \\
\text { Atual de IB }\end{array}$ & $\begin{array}{l}\text { Atitude em Relação ao Uso de IB; Norma Subjetiva; Controle } \\
\text { Comportamental Percebido; Vantagem Relativa; Compatibilidade; } \\
\text { Complexidade; Influências Normativas; Auto-eficácia; Condições } \\
\text { Facilitadoras }\end{array}$ & $\begin{array}{l}\text { TPB } \\
\text { DTPB } \\
\text { TRA }\end{array}$ & Taiwan \\
\hline \begin{tabular}{|l|} 
Tero, Kari, \\
Karjaluoto e \\
Pahnila (2004) \\
\end{tabular} & Uso Atual de IB & $\begin{array}{l}\text { Utilidade Percebida; Facilidade Percebida de Utilizar; Diversão } \\
\text { Percebida; Quantidade de Informações Sobre IB; Segurança e } \\
\text { Privacidade Percebidas; Qualidade da Conexão com Internet }\end{array}$ & TAM & Finlândia \\
\hline Chang (2003) & $\begin{array}{l}\text { Probabilidade } \\
\text { de Adoção do } \\
\text { IB }\end{array}$ & $\begin{array}{l}\text { Sexo, Idade, Estado Civil, Escolaridade, Renda, Grau de Exposição } \\
\text { ao IB, Reputação, Local de Moradia (área metropolitana x interior), } \\
\text { Frequiência às Agências, Lembrança do IB }\end{array}$ & IDT & Coréia \\
\hline $\begin{array}{l}\text { Chau e Lai } \\
(2003)\end{array}$ & $\begin{array}{l}\text { Atitude em } \\
\text { Relação ao Uso } \\
\text { de IB }\end{array}$ & $\begin{array}{l}\text { Personalização do IB; Serviços Aliados; Familiaridade com a } \\
\text { Tarefa; Acessibilidade; Utilidade Percebida; Facilidade Percebida de } \\
\text { Utilizar }\end{array}$ & TAM & $\begin{array}{l}\text { Hong } \\
\text { Kong }\end{array}$ \\
\hline $\begin{array}{l}\text { Gerrard e } \\
\text { Cunningham } \\
(2003)\end{array}$ & Uso Atual de IB & 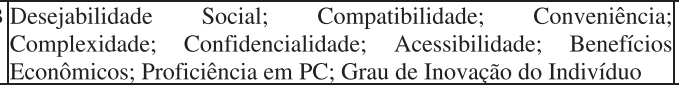 & IDT & Singapura \\
\hline
\end{tabular}




\section{(conclusão)}

\section{Tabela 1: Revisão Bibliográfica de Estudos Relacionais sobre Adoção de Internet Banking}

\begin{tabular}{|c|c|c|c|c|}
\hline Estudo & $\begin{array}{c}\text { Variáveis } \\
\text { Dependentes }\end{array}$ & Variáveis Independentes & $\begin{array}{l}\text { Teoria de } \\
\text { Suporte }\end{array}$ & País \\
\hline $\begin{array}{l}\text { Wang, Wang, } \\
\text { Lin e Tang } \\
(2003)\end{array}$ & $\begin{array}{l}\text { Intenção } \quad \text { de } \\
\text { Usar IB }\end{array}$ & $\begin{array}{l}\text { Credibilidade Percebida; Auto-eficácia em Computador; Facilidade } \\
\text { Percebida de Utilizar; Utilidade Percebida }\end{array}$ & TAM & Taiwan \\
\hline $\begin{array}{l}\text { Suh e Han } \\
(2003)\end{array}$ & $\begin{array}{l}\text { Intenção } \quad \text { de } \\
\text { Usar IB; Uso } \\
\text { Atual de IB }\end{array}$ & $\begin{array}{l}\text { Controle Comportamental Percebido; Confiança no IB; Atitude em } \\
\text { Relação à Utilização de IB; }\end{array}$ & $\begin{array}{l}\text { TRA } \\
\text { TAM }\end{array}$ & Coréia \\
\hline \begin{tabular}{|l|} 
Liao e \\
Chewung \\
$(2002)$
\end{tabular} & $\begin{array}{l}\text { Desejo de Usar } \\
\text { IB }\end{array}$ & $\begin{array}{l}\text { Utilidade do IB (Expectativas da Acurácia, Segurança, Velocidade } \\
\text { do Acesso, Facilidade de Utilizar, Envolvimento do Usuário, } \\
\text { Conveniência) }\end{array}$ & N.D. & Singapura \\
\hline $\begin{array}{l}\text { Suh e Han } \\
(2002)\end{array}$ & $\begin{array}{l}\text { Intenção } \text { de } \\
\text { Usar IB; Uso } \\
\text { Atual de IB }\end{array}$ & $\begin{array}{l}\text { Facilidade Percebida de Utilizar; Utilidade Percebida; Atitude em } \\
\text { Relação à Utilização de IB; Confiança em IB }\end{array}$ & TAM & Coréia \\
\hline $\begin{array}{l}\text { Tan e Teo } \\
(2000)\end{array}$ & $\begin{array}{l}\text { Intenção de usar } \\
\text { IB }\end{array}$ & $\begin{array}{l}\text { Vantagem Relativa; Compatibilidade (valores, experiência com a } \\
\text { Internet, necessidades bancárias); Complexidade; Testagem; Risco; } \\
\text { Normas Subjetivas; Auto-eficácia; Condições Facilitadoras } \\
\text { (Disponibilidade de suporte governamental, Disponibilidade de } \\
\text { suporte tecnológico) }\end{array}$ & DTPB & Singapura \\
\hline
\end{tabular}

Como também pode ser visto pela análise da Tabela 1, em estudos transversais, a adoção de novas tecnologias como o Internet Banking pode ser investigada, tanto a partir da perspectiva daqueles que já adotaram a inovação tecnológica quanto da perspectiva daqueles que ainda não a adotaram. Ao se investigar aqueles que já adotaram a nova tecnologia, procurase verificar quais os fatores que influenciaram, em determinado momento do passado, o comportamento de adoção. Ao se investigar aqueles que ainda não adotaram, procura-se determinar os fatores que influenciariam a intenção de adotar, pressupondo-se que a intenção é um bom estimador do comportamento (Fishbein \& Ajzen, 1975).

A vantagem de se investigar aqueles que já adotaram a nova tecnologia é poder determinar os fatores que determinaram o comportamento em si e não apenas a intenção de comportamento. Entretanto a desvantagem é que a as percepções deste grupo de indivíduos revelam uma decisão tomada no passado, percepções estas que podem estar mascaradas pela passagem do tempo e pela experiência adquirida na utilização da tecnologia.

A vantagem de se investigar usuários potenciais é que suas percepções não são influenciadas nem pelo tempo nem pela experiência. Entretanto, segundo Fishbein, Hennessy, Yzer e Douglas (2003), a falta de habilidades ou restrições ambientais podem impedir que a intenção se transforme em comportamento, ou seja, a intenção em determinadas condições pode não prever adequadamente um comportamento.

Entretanto, a despeito da sua desvantagem, do ponto de vista prático, 
investigar usuários potenciais de uma nova tecnologia é mais interessante, uma vez que é a este grupo que se pretende influenciar. Portanto, seguindo diversos estudos sobre a adoção do IB (por exemplo, Lee et al., 2005; Shih \& Fang, 2004; Suh \& Han, 2002, 2003; Tan \& Teo, 2000), a variável dependente do modelo é a intenção de usar o Internet Banking no futuro.

Outra característica do modelo proposto é que o constructo atitudes em relação ao comportamento não foi incluído no modelo, da mesma forma como já foi feito em estudos anteriores, utilizando o TAM (Adams, Nelson, \& Todd, 1992; Chau, 1996) e em estudos anteriores sobre adoção do IB (Brown et al., 2004; Lee et al., 2005; Tan \& Teo, 2000).

A presença da atitude em relação ao comportamento de adoção pode aumentar a capacidade de explicação do modelo. Entretanto este constructo tem menor relevância do ponto de vista gerencial, uma vez que as ações mercadológicas destinadas a alterar a percepção sobre as características da inovação têm como foco as crenças dos indivíduos. Uma vez alteradas as crenças sobre uma nova tecnologia, é natural supor que as atitudes sobre a sua adoção também se tornem mais positivas e culminem na adoção efetiva da nova tecnologia (Fishbein \& Ajzen, 1975).

Portanto, o modelo se propõe a investigar o impacto direto das crenças atitudinais, normativas e de controle sobre a intenção de comportar-se. A Figura 1 contém a representação gráfica do modelo proposto: os sinais entre parênteses após cada variável indicam o tipo de influência - positiva ou negativa - sobre a intenção de adotar o IB.

\section{MÉTODO}

\section{Participantes}

Foram entrevistadas para este estudo apenas pessoas que possuíam pelo menos uma conta corrente bancária e nunca haviam utilizado o Internet Banking até o momento da entrevista. Os respondentes foram selecionados por conveniência e abordados nas proximidades de agências bancárias em diversos pontos de uma grande capital brasileira. Os dados foram coletados por meio de levantamento, utilizando um questionário estruturado e as entrevistas foram feitas de forma pessoal e individual. 


\section{Figura 1: Modelo Teórico Proposto para Adoção do IB Entre Não Usuários}

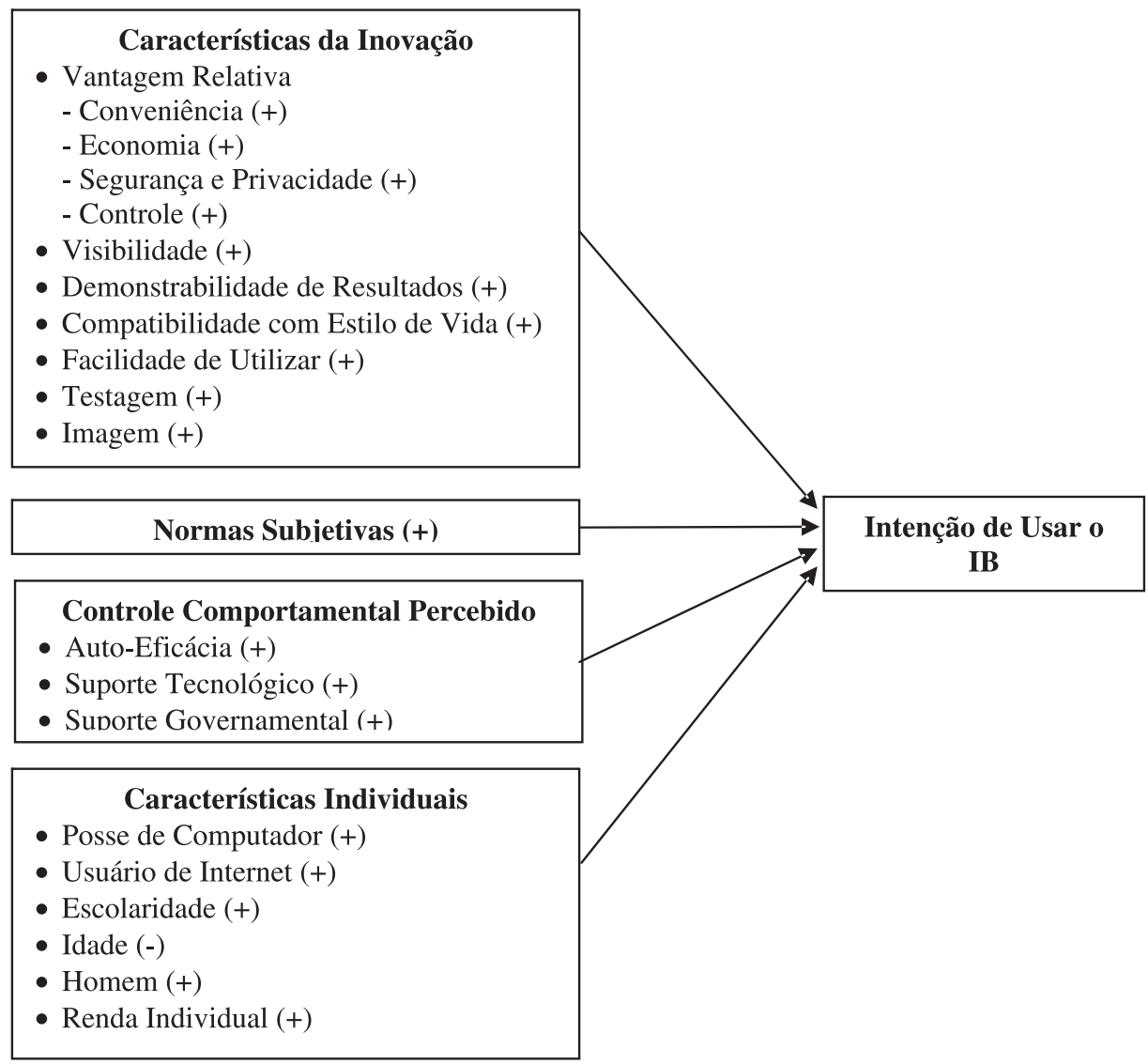

\section{Escalas}

Todos os itens dos constructos latentes deste estudo são mensurados por meio de escalas do tipo Likert com 6 pontos ( $1=$ discordo totalmente; $6=$ concordo totalmente). Os itens dos constructos visibilidade, demonstrabilidade de resultados, facilidade de utilizar, testagem e imagem foram traduzidos para a língua portuguesa, a partir das escalas desenvolvidas por Moore e Benbasat (1991). Por ter sido desenvolvida para investigar a adoção de novas tecnologias em ambientes organizacionais, a escala de compatibilidade de Moore e Benbasat capta apenas a compatibilidade da tecnologia com o tipo de trabalho que o potencial adotante exerce e, por esta razão, não foi utilizada neste estudo. Foi dada preferência para a tradução da escala de compatibilidade utilizada por Tan e Teo (2000), que investigaram a adoção de IB entre potenciais usuários. 
Como o constructo vantagem relativa foi decomposto, os itens que operacionalizam cada um dos subconstructos foram criados especificamente para este estudo. Assim, os itens do constructo vantagem relativa de conveniência estão definidos em função das vantagens de conveniência que o IB oferece: estar disponível 24 horas por dia todos os dias do ano, ser possível fazer transações de qualquer lugar, ser mais rápido e economizar tempo. Os itens do constructo vantagem relativa de segurança e privacidade estão definidos em função das preocupações comuns dos usuários de Internet, como a possibilidade de roubo de informações, o roubo de identidade ou a venda das informações (Lieberman \& Stashevsky, 2002). Os itens do constructo vantagem relativa de economia, por sua vez, procuram captar a percepção sobre o custo das transações realizadas pela Internet e sobre as tarifas cobradas para se utilizar o IB. Os itens relacionados ao constructo vantagem relativa de controle referem-se à possibilidade de controle sobre as transações que o IB permite: O IB daria maior controle sobre as finanças pessoais; O IB permitiria programar pagamentos de contas; e O IB permitiria recuperar transações mais antigas.

Conforme a definição de norma subjetiva ("a percepção de um indivíduo de que a maioria das pessoas que são importantes para ele acredita que deveria ou não se comportar de uma determinada maneira", Fishbein \& Ajzen, 1975, p. 302), os itens desta escala estão definidos em relação à influência que os amigos, familiares e colegas de trabalho podem exercer sobre a adoção do Internet Banking.

Os itens do constructo auto-eficácia foram traduzidos para a língua portuguesa, a partir da escala de Compeau e Higgins (1995), enquanto os itens do constructo suporte governamental foram traduzidos a partir da escala de Tan e Teo (2000). Já os itens de suporte tecnológico foram criados especificamente para este estudo e procuram capturar a segurança e facilidade que a tecnologia da Internet proporciona às pessoas que utilizam o IB.

Os três itens do constructo intenção de usar o IB estão formulados de modo semelhante a outros estudos sobre adoção de IB (por exemplo, Suh \& Han, 2002; Tan \& Teo, 2000) e procuram capturar a intenção de o respondente utilizar pessoalmente o IB, bem como encorajar e recomendar aos amigos e parentes o uso do IB.

Todos os itens de escalas publicadas originalmente em inglês foram traduzidos pelos autores deste estudo e em seguida submetidos a um tradutor profissional para consistência. A seguir, estes itens foram submetidos a três acadêmicos de marketing para que analisassem seu conteúdo. Depois de algumas discussões entre os autores do estudo e estes avaliadores, algumas alterações foram feitas. A seguir, o questionário foi pré-testado com seis estudantes de pós-graduação. 
Algumas perguntas tiveram que ser reformuladas para melhorar a sua clareza. No estágio final, o questionário foi pré-testado com 7 respondentes. Após este último pré-teste, ainda foram necessárias pequenas alterações. Os itens de todos os constructos discutidos nesta seção estão descritos no Anexo 1.

\section{Resultados}

\section{Características da Amostra}

Compõem a amostra deste estudo 292 indivíduos que nunca haviam utilizado Internet Banking no momento da coleta de dados. Destes 292 indivíduos, 144 (49\%) nunca haviam usado a Internet e 148 (51\%) já usavam a Internet, embora nunca tivessem usado o IB.

A maioria (61\%) dos entrevistados era do sexo feminino e $45 \%$ dos entrevistados eram casados. Em relação à faixa etária, $6 \%$ tinham até 20 anos de idade, $49 \%$ tinham entre 21 e 40 anos e $45 \%$ tinha mais de 40 anos de idade. Em relação ao grau de escolaridade, $40 \%$ tinham algum curso superior, completo ou incompleto; $35 \%$ dos respondentes recebiam mais do que $\mathrm{R} \$ 1.500,00$ por mês.

Quando perguntados em que bancos faziam a maior parte do seu movimento financeiro, $20 \%$ dos respondentes mencionaram o Itaú e 19\% o Bradesco; Banco do Brasil e Banespa/Santander foram mencionados por 13\% dos respondentes cada um; ainda, $12 \%$ citaram o Banco Real, $11 \%$ mencionaram o Unibanco e $9 \%$ o HSBC, enquanto outros bancos foram mencionados por 3\% dos respondentes. Em média, os respondentes tinham conta corrente em seus bancos principais há 8 anos.

\section{Validade, Dimensionalidade e Confiabilidade dos Constructos}

A validade de conteúdo, "grau no qual um conjunto específico de itens reflete o conteúdo de um domínio" (DeVellis, 2003, p. 49), foi estabelecida durante a elaboração do questionário pela utilização de escalas já validadas na literatura, pela análise cuidadosa dos itens durante a tradução e pelo desenvolvimento criterioso de novos itens.

Um dos pressupostos de um constructo latente é a sua unidimensionalidade: grau no qual um conjunto de itens compartilham um constructo comum (DeVellis, 2003, p. 94). Hair, Anderson, Tatham e Black (1998) sugerem que a análise fatorial desempenha um papel principal na avaliação da dimensionalidade de um 
constructo, por determinar o número de fatores de um conjunto de dados e as cargas fatoriais de cada item em seus respectivos constructos.

Assim, todos os itens das variáveis independentes foram submetidos a uma análise fatorial exploratória. Deu-se preferência ao método de extração por componentes principais e os resultados foram submetidos à rotação pelo método Varimax. O número de fatores se restringiu ao número exato (13) de constructos analisados. Os itens do constructo vantagem relativa de economia foram excluídos do estudo, porque o número de respostas em branco foi superior a $25 \%$ das respostas válidas. Este fato ocorreu, porque muitos respondentes, por nunca terem tido acesso ao IB, não souberam dizer se era mais barato fazer transações pelo IB ou se as tarifas eram menores.

Na primeira fase da análise fatorial procuravam-se itens que não tivessem cargas fatoriais bem definidas em seus respectivos constructos (Hair et al., 1998). Desta forma, cinco itens foram excluídos das análises subseqüentes, deixando três constructos com apenas um indicador: facilidade de usar, suporte governamental e suporte tecnológico.

Uma segunda análise fatorial exploratória foi realizada e, nesta solução, verificouse que os 13 fatores eram responsáveis por 86,0\% da variância de todos os itens. A comunalidade extraída de todos os itens foi superior a 0,7 - a menor comunalidade extraída foi 0,75 e a maior 0,99 (Hair et al., 1998 sugerem um limite inferior de 0,5 ) e não se verificaram cargas fatoriais cruzadas superiores a 0,35. A carga fatorial de todos os itens em seus respectivos constructos foi superior a 0,7 (ver Anexo 1).

Os testes sobre a adequação da análise fatorial também foram satisfatórios. $\mathrm{O}$ teste de esfericidade de Bartlett detecta a presença de correlações entre o conjunto de variáveis incluídas na análise e seu resultado foi significativo ao nível de $1 \%$ $\left(\chi^{2} 630\right.$ d.f. $\left.=7.947, \mathrm{p}<0,01\right)$. Por sua vez, o teste Kaiser-Meyer-Olkin é uma medida de adequação amostral que procura detectar se as correlações parciais entre as variáveis são pequenas e, neste caso, foi igual a 0,865 , superior ao limite inferior de 0,7 sugerido por Hair et al. (1998).

Confiabilidade é a proporção da variância que pode ser atribuída ao verdadeiro valor da variável latente (DeVellis, 2003, p. 27). Uma das formas mais comuns de se avaliar a confiabilidade de uma escala é examinando-se a sua consistência interna pelo cálculo do coeficiente Alpha de Cronbach (DeVellis, 2003). Como se pode perceber pelos dados relatados no Anexo 1, o coeficiente Alfa de Cronbach foi superior a 0,7 (Nunnally, 1978) para todos os constructos multi-itens. Após todos estes testes, os constructos latentes foram obtidos a partir da média dos seus respectivos itens. 
O coeficiente Alfa de Cronbach para os itens da intenção de uso do IB foi igual a 0,97 , também superior ao limite de 0,7 ; o valor deste constructo também foi calculado a partir da média dos seus três indicadores.

\section{Teste do Modelo}

Estudos anteriores que investigaram a adoção de IB utilizaram basicamente uma de três técnicas estatísticas para teste dos modelos propostos: análise de regressão logística binomial ou multinomial, modelagem por equações estruturais e análise de regressão linear múltipla. A análise de regressão logística aplica-se, quando a variável dependente é de natureza nominal ou ordinal (Hair et al., 1998). Embora estritamente falando a intenção de usar o IB tenha natureza ordinal, já se tornou tradição na literatura de marketing considerar que escalas do tipo Likert possuem natureza intervalar (Malhotra, 1999). Portanto a análise de regressão logística não é a melhor alternativa para o presente caso.

A técnica de modelagem por equações estruturais é indicada para a comparação de modelos teóricos alternativos (Joreskög, 1993) e tem sido especialmente utilizada para examinar relações de antecedência e conseqüência entre variáveis latentes (Byrne, 1998). Para utilizar a técnica de modelagem por equações estruturais recomenda-se que cada constructo latente possua pelo menos três indicadores, sendo aceitável no mínimo dois indicadores (Byrne, 1998).

No presente caso, entretanto, esta técnica não poderia ser utilizada, considerando-se que, após a análise fatorial, três constructos latentes (facilidade de usar o IB, suporte governamental e suporte tecnológico) ficaram com apenas um indicador após a análise fatorial exploratória. Além do mais, as variáveis individuais, do ponto de vista teórico, não constituem um constructo latente único e devem ser examinadas isoladamente, o que também impede a utilização da técnica de equações estruturais.

Uma alternativa à modelagem de equações estruturais seria consolidar as variáveis latentes a partir dos seus indicadores e utilizar o método de análise de caminhos. Neste caso, entretanto, considerando-se que o modelo contém apenas uma variável dependente, o resultado seria equivalente à regressão linear múltipla.

Portanto, considerando a maior facilidade de compreensão da regressão linear múltipla e a facilidade de aplicação pela indústria bancária, para se testar o modelo proposto deu-se preferência a este método. Os resultados da regressão da intenção de usar o IB sobre as variáveis independentes do modelo proposto podem ser vistos na Tabela 2.

O modelo é significativo $\left(\mathrm{F}_{20,265}=13.409, \mathrm{p}<0,01\right)$ e o coeficiente de explicação 
ajustado para o modelo é igual a 46,5\%. Para verificar a consistência do modelo, os resíduos foram analisados em busca de divergências em relação aos pressupostos da regressão linear: linearidade, homoscedasticidade e normalidade. A análise gráfica dos resíduos permite concluir que a sua distribuição é aproximadamente normal; de fato, o teste Kolmogorov-Smirnov conduz à rejeição da hipótese de que a distribuição dos resíduos não é normal ( $\mathrm{z}=0,657, \mathrm{p}=0,782)$. Desta forma, embora tenha sido detectado que a hipótese de normalidade da maioria das variáveis independentes seja rejeitada, a robustez do método de regressão linear em relação à hipótese de não normalidade das variáveis independentes parece não influenciar os resultados.

A análise dos resultados da Tabela 2 permite concluir que o efeito de 8 variáveis latentes, dentre as vinte do modelo completo (treze considerando apenas as crenças), é significativo. No nível de confiança de 1\%, são significativos os coeficientes das variáveis independentes compatibilidade com estilo de vida, normas subjetivas, auto-eficácia e imagem; no nível de confiança de 5\%, são significativos os coeficientes das variáveis vantagem relativa de segurança e privacidade, vantagem relativa de controle, testagem e suporte tecnológico. É importante notar que o sinal do coeficiente da variável testagem é oposto à hipótese do modelo, isto é, segundo os resultados, quanto maior a oportunidade que o indivíduo teve de testar o IB, menor a intenção de usar o IB.

Tabela 2: Resultado da Análise de Regressão Múltipla ${ }^{a}$

\begin{tabular}{|c|c|c|c|c|c|c|}
\hline \multirow[b]{2}{*}{$\begin{array}{l}\text { Grupo de } \\
\text { Variáveis }\end{array}$} & \multirow[b]{2}{*}{ Variável Independente } & \multicolumn{2}{|c|}{$\begin{array}{c}\text { Coef. não } \\
\text { Padronizados }\end{array}$} & $\begin{array}{c}\text { Coef. } \\
\text { Padronizados }\end{array}$ & \multirow[b]{2}{*}{$\mathrm{t}$} & \multirow[b]{2}{*}{ Sig. } \\
\hline & & B & $\begin{array}{c}\text { Erro } \\
\text { Padrão }\end{array}$ & Beta & & \\
\hline & (Constante) &,- 265 &, 452 & &,- 586 & ,558 \\
\hline \multirow{9}{*}{$\begin{array}{c}\text { Características da } \\
\text { Inovação }\end{array}$} & Vantagem Relativa Conveniência &,- 116 & 081 &,- 080 & $-1,428$ &, 155 \\
\hline & Vantagem Relativa Segurança e Privacidade & ,156 & ,070 & ,126 & 2,247 & ,025 \\
\hline & Vantagem Relativa Controle & ,198 & ,077 & ,156 & 2,576 & ,011 \\
\hline & Visibilidade & 026 & 061 & 024 & 422 & 673 \\
\hline & Capacidade de Demonstrar Resultados &,- 010 & 079 &,- 008 &,- 124 & ,902 \\
\hline & Compatibilidade com Estilo de Vida & ,235 & ,067 & ,214 & 3,493 & ,001 \\
\hline & Facilidade de Usar &,- 037 & 054 &,- 032 &,- 671 & ,503 \\
\hline & Testagem &,- 120 & ,058 &,- 100 & $-2,047$ & ,042 \\
\hline & Imagem &, 181 &, 064 &, 152 & 2,846 &, 005 \\
\hline Normas Subjetivas & Normas Subjetivas &, 197 & ,068 & ,145 & 2.884 &, 004 \\
\hline \multirow{3}{*}{$\begin{array}{c}\text { Controle } \\
\text { Comportamental } \\
\text { Percebido }\end{array}$} & Auto-eficácia & 294 & ,074 & ,245 & 3,993 &, 000 \\
\hline & Suporte Tecnológico & ,135 & ,062 & ,112 & 2,167 & ,031 \\
\hline & Suporte Governamental & 018 & 049 & 017 &, 367 & 714 \\
\hline \multirow{7}{*}{$\begin{array}{l}\text { Características } \\
\text { Individuais }\end{array}$} & Respondente é usuário de Internet &,- 357 & ,171 &,- 113 & $-1,480$ & ,139 \\
\hline & Respondente tem computador em sua residência &, 050 &, 161 & ,016 & 311 & ,756 \\
\hline & Respondente é solteiro & 184 &, 154 & 057 & 1,193 & ,234 \\
\hline & Respondente tem entre 21 e 40 anos de idade & 012 &, 148 & ,004 &, 078 & ,938 \\
\hline & Respondente tem curso superior &,- 056 &, 161 &,- 017 &,- 346 &, 730 \\
\hline & Respondente tem renda superior a 1500 reais &,- 146 & 171 &,- 044 &,- 852 & 395 \\
\hline & Respondente é homem &,- 003 &, 152 &,- 001 &,- 020 & ,984 \\
\hline
\end{tabular}

a Variável dependente: Intenção de Usar o IB. 
Nenhum coeficiente associado às variáveis individuais se mostra significativo. Isto significa que, para a amostra investigada, apenas as crenças sobre o IB influenciam a intenção de adotar o Internet Banking; mas não características individuais como ser ou não usuário da Internet, posse de computador, estado civil, idade, escolaridade, renda e sexo.

Um dos maiores problemas em análises de regressão é a existência de multicolinearidade, especialmente com grande número de variáveis independentes, como a que foi analisada aqui. A existência de multicolinearidade pode reduzir o valor do coeficiente de determinação do modelo, diminuir ou até mesmo eliminar o efeito de variáveis independentes e, no limite, provocar a inversão do sinal do coeficiente de variáveis altamente correlacionadas (Hair et al., 1998). Estes autores sugerem duas formas de identificar a existência de multicolinearidade: análise das correlações entre as variáveis independentes e análise dos valores da tolerância ou do fator de inflação da variância (VIF, pela sigla em inglês de Variance Inflation Factor). Para Hair et al. (1998), valores superiores a 0,9 de correlação bivariada e valores do VIF superiores a 10 indicam a existência de multicolinearidade.

A análise dos coeficientes de correlação de Spearman revelou que as correlações entre as 20 variáveis independentes do modelo variam entre 0 e 0,615 e, dentre as 180 correlações possíveis, apenas 4 são superiores a 0,5. Por sua vez, os valores do VIF se situam entre 1,15 e 2,36. Assim, estes resultados sugerem que não há multicolinearidade entre as variáveis independentes do modelo.

\section{Discussão}

De modo geral, os resultados do modelo proposto neste estudo sugerem que sua capacidade de explicação da intenção em adotar o IB é ligeiramente superior aos resultados de estudos anteriores, envolvendo a adoção de novas tecnologias. O coeficiente de explicação ajustado para o modelo analisado é de 46,5\%; segundo Venkatesh et al. (2003), os modelos usuais sobre adoção de inovações "rotineiramente explicam cerca de $40 \%$ da variância da intenção individual de usar uma tecnologia" (p. 40).

Da mesma forma, os resultados do modelo analisado aqui superam os resultados obtidos por diversos estudos anteriores sobre adoção de Internet Banking, especialmente levando-se em conta que muitos destes estudos utilizam como técnica de análise de dados a modelagem de equações estruturais e incluem entre as variáveis explicativas a atitude em relação à adoção do Internet Banking, fato que tende a inflar a capacidade de explicação da variável dependente. 
Os resultados também permitem concluir que oito dos coeficientes das variáveis relacionadas às crenças têm efeito significativo e é possível excluir como explicação dos resultados os efeitos de multicolinearidade, uma vez que testes específicos não detectaram a sua presença.

Embora não seja possível a comparação direta com resultados de estudos anteriores, uma vez que esta é a primeira vez que um estudo sobre adoção de IB reúne um número tão grande de variáveis explicativas, alguns pontos são interessantes de serem notados.

A primeira observação relevante é que as duas variáveis do TAM (um dos modelos mais difundidos na adoção de novas tecnologias) incluídas no modelo utilidade percebida, aqui decomposta em vantagens relativas e facilidade de usar - não são as que exercem maior impacto sobre a intenção de usar o IB. De acordo com os resultados (Tabela 2), o constructo que parece exercer maior impacto sobre a intenção de vir a usar o IB é a auto-eficácia. Este constructo refere-se à autoconfiança que um indivíduo demonstra em sua habilidade para adotar determinado comportamento (Bandura, 1977); neste estudo, auto-eficácia refere-se à confiança do indivíduo em utilizar de forma autônoma o IB. Este resultado não chega a surpreender, levando-se em conta que as informações bancárias têm caráter sigiloso e é razoável supor que o usuário potencial perceba como fundamental para a adoção do IB a habilidade em utilizar o IB de forma autônoma, para garantir acesso exclusivo às suas informações.

Ainda em relação às duas variáveis do TAM, é interessante notar que apenas dois dos constructos de vantagens relativas (segurança e privacidade e controle) são significativos para o modelo, enquanto o constructo facilidade de utilizar o IB não é significativo. Davis (1989) e Davis et al. (1989) já haviam relatado que a percepção de utilidade é mais relevante para a adoção de nova tecnologia do que a facilidade de usá-la e que o interessado na adoção de nova tecnologia deve preocupar-se muito mais com a sua utilidade do que com a facilidade de utilizá-la.

A vantagem de decompor as crenças, como sugerido por Taylor e Todd (1995), é que se pode identificar que as vantagens relativas com maior impacto sobre a intenção de usar o IB se referem às maiores preocupações dos usuários na utilização da Internet: privacidade, segurança e controle.

Por outro lado, a vantagem relativa de conveniência não é percebida como relevante para a adoção do IB. Este resultado sinaliza que a possibilidade de realizar transações bancárias em qualquer momento, de qualquer lugar ou mesmo com maior rapidez e economia não exerce influência sobre o processo de adoção do IB. Pode ter contribuído para esta percepção o fato de que a maioria das transações bancárias realizadas pelo IB somente é efetivada durante o expediente 
bancário ou o fato de que o IB não proporciona solução para uma das maiores necessidades que aflige os usuários do sistema bancário fora do expediente bancário, que é a necessidade de dinheiro em espécie.

Duas crenças também muito relevantes para a capacidade de explicação do modelo são a compatibilidade com o estilo de vida e a imagem. Estes dois constructos estão muito relacionados, uma vez que o constructo compatibilidade com o estilo de vida reflete a visão que o indivíduo faz de si e como o IB está associado a esta perspectiva, enquanto o constructo imagem reflete a visão que ele imagina que os outros terão dele, caso ele passe a utilizar o IB. Em linha com este resultado também está a importância das normas subjetivas para a adoção do IB. O ponto em comum entre a imagem e as normas subjetivas é a importância da opinião de outras pessoas para o processo de adoção do IB.

Os resultados também mostram que, enquanto o suporte tecnológico é significativo para explicar a intenção de adotar o IB, o mesmo não acontece com o suporte governamental. Estes resultados revelam que, se por um lado existe confiança na tecnologia que suporta a Internet, por outro lado não existe a percepção de que o governo (ou qualquer de suas instâncias) se esforce em aumentar a sua disseminação.

Uma das maiores surpresas entre os resultados é o sinal trocado do constructo testagem. Teoricamente, quanto maior a possibilidade de se experimentar uma nova tecnologia, maior a probabilidade de que ela venha a ser adotada. Entretanto os resultados mostram exatamente o contrário, isto é, quanto maiores os esforços dos bancos em proporcionar acesso dos seus correntistas ao IB, menor intenção eles demonstram em adotá-lo.

Uma das explicações para este resultado é que os esforços dos bancos, ao proporcionar testes para o acesso ao IB tenham sido tão frustrantes, a ponto de desestimular seus correntistas a adotá-lo. Outra hipótese é que este resultado pode refletir alguma desconfiança dos indivíduos em relação às verdadeiras intenções dos bancos que se esforçam para que eles testem o IB ou ainda indicar a insatisfação dos respondentes com os seus bancos, ao acreditarem que eles deveriam ter disponibilizado testes de acesso ao IB e os bancos não o fizeram. Investigações adicionais são necessárias a este respeito.

Dentre o conjunto de crenças do modelo proposto, os constructos visibilidade e demonstração de resultados também não se mostram significativos, ao explicar a intenção de usar o IB. Uma provável explicação para este resultado é que o acesso ao Internet Banking geralmente é feito de forma individual e solitária e pessoas que ainda não utilizam o IB tiveram pouca ou nenhuma oportunidade de ver outras pessoas usando o sistema. Se os adotantes potenciais não viram outras 
pessoas utilizando o IB ou a experiência proporcionada pelos bancos não é satisfatória, como sugerido no parágrafo anterior, torna-se difícil para eles avaliar exatamente o que é o IB e que resultados podem ser esperados com a sua utilização, tornando estes constructos irrelevantes para a sua adoção.

Finalmente, é importante ressaltar que nenhuma das variáveis individuais se mostra significativa, ao explicar a intenção de adotar o IB, sugerindo que a intenção de adotar o IB é determinada exclusivamente pelas crenças associadas ao IB. A este respeito é muito interessante notar que nem mesmo a prévia utilização da Internet ou a posse de um computador pessoal se mostram determinantes da intenção de vir a utilizar o IB, contrariando estudos anteriores que mostraram que a experiência anterior com uma tecnologia pode influenciar a sua adoção futura (Chau \& Lai, 2003; Karahanna \& Straub, 1999).

\section{Implicações Gerenciais e Conclusões}

Este estudo tem como objetivo propor e testar um modelo que permita identificar os fatores que influenciam a adoção do Internet Banking no Brasil entre não usuários. Uma preocupação que sempre esteve presente era o desenvolvimento de um modelo teórico abrangente e cujo teste fosse relativamente simples, para que sua aplicação pela indústria bancária fosse a mais ampla possível.

Este objetivo foi plenamente atingido na medida em que o modelo proposto possui grande capacidade de explicação da intenção de adoção do IB entre não usuários e é relativamente simples de ser colocado em prática.

Para tanto, ao contrário de estudos anteriores sobre adoção de IB, o modelo testado aqui não sugere a inclusão de nenhum constructo inédito na literatura. Ao contrário disto, o modelo proposto reúne apenas os construtos de alguns dos modelos mais consagrados na literatura de marketing sobre adoção de novas tecnologias, o que acabou eliminando o fenômeno da multicolinearidade presente em diversos estudos.

Os resultados do estudo com uma amostra composta por usuários de diversos bancos brasileiros, residentes numa grande capital brasileira, permitem identificar amplo conjunto de variáveis que se mostram significativas, ao influenciar a intenção de usar o IB. Dos 13 constructos relacionados a crenças do modelo, o efeito de oito deles se mostra significativo sobre a intenção de adotar o IB. São eles, em ordem de importância: auto-eficácia, compatibilidade com estilo de vida, vantagem relativa de controle, imagem, normas subjetivas, vantagem relativa de segurança e privacidade, suporte tecnológico e testagem. Por outro lado, nenhuma variável 
individual se mostrou significativa, ao influenciar a intenção de adotar o IB. Devese, lembrar, entretanto, que o sinal do coeficiente do constructo testagem foi contrário ao que era esperado, reduzindo a importância deste constructo para esta amostra.

Utilizando-se deste modelo como base, um banco pode conduzir uma pesquisa entre os seus clientes que ainda não utilizam o IB para identificar que fatores influenciam a sua adoção desta ferramenta. A partir daí, com base nos resultados, é possível que um banco desenvolva programas estratégicos para estimular os seus clientes a adotarem o IB.

Para se ter uma idéia de como os resultados deste estudo podem ser aplicados gerencialmente, tome-se inicialmente o constructo imagem. Imagem refere-se ao grau em que um indivíduo percebe que uma inovação possa elevar seu status entre o seu grupo social. Desta forma, um banco poderia desenvolver propagandas em que se reforça a mensagem de que o IB melhorará a imagem do indivíduo, tornando-o uma pessoa de mais prestígio e mais "antenada" com o seu tempo.

Como outro exemplo, tome-se a variável visibilidade. Visibilidade refere-se à percepção de um indivíduo de que a inovação é capaz de ser observada em uso. Para incentivar as pessoas a adotar o IB, um banco poderia disponibilizar terminais de acesso ao Internet Banking em agências bancárias, shopping centers, aeroportos e outros locais de grande circulação de pessoas para que os indivíduos pudessem tanto observar quanto experimentar o IB.

Como outro exemplo, considerem-se os constructos vantagem relativa de segurança e privacidade e vantagem relativa de controle. Sabendo que estas variáveis influenciam positivamente a intenção de vir a adotar o IB, um banco deveria passar a enfatizar em toda a sua comunicação sobre o IB que ele proporciona maior segurança e privacidade que os métodos normais de acesso ao banco e que as funcionalidades do IB permitem ao indivíduo ter maior controle sobre a sua vida financeira.

Como último exemplo, tome-se a variável norma subjetiva. Um banco poderia implementar uma promoção pela qual os atuais usuários de IB ganhariam prêmios, se eles incentivassem seus amigos correntistas a também utilizar o IB. Existem muitas outras possibilidades de explorar os resultados deste estudo para propor ações estratégicas que tenham por objetivo incentivar as pessoas a utilizarem o IB.

Por outro lado, também é interessante saber quais as variáveis que não influenciam a intenção de adotar o IB. Por exemplo, o fato de que uma pessoa que já utiliza a Internet não tem maior intenção de adotar o IB do que uma pessoa que não utiliza a Internet sugere que a Internet não é bom meio para nela veicular 
propaganda sobre o IB. Da mesma forma, parece que financiar um computador com a esperança de que o indivíduo venha a adotar o IB também não é estratégia promissora.

Portanto, a maior contribuição do estudo é a proposta de um modelo abrangente, simples, facilmente implementável e com alta capacidade de explicação da intenção de adoção do IB. Ressalte-se que não se encontrou na literatura sobre adoção de Internet Banking nenhum estudo anterior que tenha proposto um conjunto tão amplo de variáveis explicativas para a intenção de uso do IB.

Da forma como foi proposto, o modelo tem algumas vantagens sobre modelos concorrentes. Uma delas é que o modelo pode ser adaptado facilmente para analisar a adoção de diversos tipos de tecnologia, bastando para tanto adequar as escalas ao tipo de tecnologia analisado. Outra vantagem é que, por eliminar relações intermediárias entre os constructos, permite a fácil identificação das variáveis que influenciam diretamente a intenção de adotar.

Apesar da importância dos resultados do estudo, é importante salientar as suas limitações. Uma delas fica por conta da mensuração de alguns itens. Como foi mencionado, o constructo vantagem relativa de economia teve de ser eliminado do estudo, porque muitas pessoas preferiram não se manifestar sobre as perguntas relativas à economia do IB em relação a outras formas de acesso ao banco.

Outro problema identificado é que, durante a análise fatorial, 5 itens tiveram de ser excluídos, reduzindo a mensuração de 3 constructos latentes (facilidade de usar, suporte tecnológico e suporte tecnológico) a um único item, o que pode ter prejudicado os resultados obtidos. Quanto à amostra, a seleção por conveniência dos respondentes em uma única cidade brasileira impede a generalização dos resultados aqui obtidos.

Do ponto de vista teórico, deve-se reconhecer a possibilidade de que existam relações de moderação ou intermediação entre as variáveis independentes do modelo. Estudos futuros poderiam examinar outras relações que não foram previstas neste modelo e que poderiam aumentar a capacidade de explicação da variável dependente. Entretanto a análise de modelos mais complexos só seria possível por meio de análise de equações estruturais, algo que não foi possível aqui, devido às limitações impostas pelo número de indicadores de algumas variáveis latentes e das variáveis individuais.

Assim, esse estudo abre diversas possibilidades de investigações futuras. A primeira delas é o refinamento dos constructos propostos, em especial o constructo vantagem relativa de economia. A segunda oportunidade é a investigação de relações mais complexas entre as variáveis independentes do modelo. Finalmente, 
propõe-se que o modelo proposto aqui seja utilizado para se investigar a adoção de outras tecnologias, mesmo que não relacionadas à indústria bancária.

\section{Artigo recebido em 08.06.2006. Aprovado em 07.01.2008.}

\section{ReferênCIAS Bibliográficas}

Adams, D. A.,

Nelson, R. R., \&

Todd, P. A. (1992).

Perceived usefulness, ease of use, and usage of information technology: a replication. MIS Quarterly, 16(2), 227-247.

Ajzen, I. (1985).

From intentions to actions: a theory of planned behaviour. In J. Kuhl \& J. Beckman (Eds.). Action-control: from cognition to behaviour. Heidelberg: Springer.

Arkinci, S.,

Aksoy, S., \&

Atilgan, E. (2004).

Adoption of internet banking among sophisticated consumer segments in an advanced developing country. The International Journal of Bank Marketing, 22(3), 212-232.

Bandura, A. (1977).

Self-efficacy: toward a unifying theory of behavioral change. Psychological Review, 84(2), 191-215.

Brown, I.,

Hoppe, R.,

Mugera, P., \&

Newman, P. (2004).

The impact of national environment on the adoption of internet banking: comparing Singapore and South Africa. Journal of Global Information Management, 12(2), 1-25.

Byrne, B. M. (1998).

Structural equation modeling with Lisrel, Prelis, and Simplis: basic concepts, applications, and programming. Mahwah, NJ: Lawrence Erlbaum Associates.

Chan, S. C., \&

Lu, M. T. (2004).

Understanding internet banking adoption and use behavior: a Hong Kong perspective. Journal of Global Information Management, 12(3), 2143.

Chang, Y. T. (2003).

Dynamics of banking technology adoption: an application to internet banking. Royal Economic Society Annual Conference, 41. Recuperado em 15 Abril, 2006, de http:// ideas.repec.org/p/ecj/ac2003/41.html

Chau, P. Y. K. (1996).

An empirical assessment of a modified technology acceptance model. Journal of Management Information Systems, 13(2), 185-204. 
Chau, P. Y. K., \&

Lai, V. S. K. (2003).

An empirical investigation of the determinants of user acceptance of internet banking. Journal of Organizational Computing \& Electronic Commerce, 13(2), 123-145.

Compeau, D. R., \&

Higgins, C. A. (1995).

Computer self-efficacy: development of a measure and initial test. MIS Quarterly, 19(2), 189-211.

Costa, B. A., Filho (2002).

Modelo de influências na adoção de inovação: um estudo para internet banking. Tese de doutorado não publicada. Universidade de São Paulo, São Paulo, SP. Brasil.

Davis, F. D. (1986).

A technology acceptance model for empirically testing new end-user information systems: theory and results. Doctoral dissertation, Sloan School of Management, Massachusetts Institute of Technology, Boston, EUA.

Davis, F. D. (1989).

Perceived usefulness, perceived ease of use, and user acceptance of computer technology. MIS Quarterly, 13(3), 319-340.

Davis, F. D.,

Bagozzi, R. P., \&

Warshaw, P. R. (1989).

User acceptance of computer technology: a comparison of two theoretical models. Management Science, 35(8), 982-1003.
Devellis, R. F. (2003).

Scale development. Theory and applications. Thousand Oaks: Sage Publications.

Diniz, E. H. (2004).

Cinco décadas de automação. $G V-$ Executivo, 3(3), Edição Especial 50 anos, 55-60.

Eriksson, K.,

Kerem, K., \&

Nilsson, D. (2005).

Customer acceptance of internet banking in Estonia. The International Journal of Bank Marketing, 23(2-3), 200-216.

Federação Brasileira de Bancos. (2007a). Bancarização. Recuperado em 02 abril, 2008, de http://www.febraban.org.br/ Arquivo/Servicos/Dadosdosetor/ 2007/item02.asp

Federação Brasileira de Bancos. (2007b). Despesas e investimentos. Recuperado em 02 abril, 2008, de http:// www.febraban.org.br/Arquivo/ Servicos/Dadosdosetor/2007/ item16.asp

Fishbein, M., \& Ajzen, I. (1975).

Belief, attitude, intention, and behavior. An introduction to theory and research. Reading, MA: Addison-Wesley.

Fishbein, M.,

Hennessy, M.,

Yzer, M., \&

Douglas, J. (2003).

Can we explain why some people do and some people do not act on their intentions? Psychology, Health \& Medicine, 8(1), 3-18. 
Gerrard, P., \&

Cunningham, J. B. (2003).

The diffusion of internet banking among Singapore consumers. International Journal of Bank Marketing, 21(1), 16-28.

Hair, J. F., Jr.,

Anderson, R. E.,

Tatham, R. L., \&

Black, W. C. (1998).

Multivariate Data Analysis (5th ed.). Upper Saddle River, NJ: Prentice Hall.

Howcroft, B.,

Hamilton, R., \&

Hewer, P. (2002).

Consumer attitude and the usage and adoption of home-based banking in the United Kingdom. The International Journal of Bank Marketing, 20(2), 111-121.

Instituto Brasileiro de Opinião Pública e Estatística. (2006a).

Internet: o desafio da inclusão. Recuperado em 15 abril, 2006, de http:// www.ibope.com.br/calandraWeb/ servlet/CalandraRedirect?temp= $6 \&$ proj=PortalIB OPE \& pub $=$ $\mathrm{T} \& \mathrm{~d} \mathrm{~b}=\mathrm{c}$ a $l \mathrm{~d} \mathrm{~b} \& \mathrm{co} \mathrm{m} \mathrm{p}=$ pesquisa_leitura $\&$ nivel $1=$ n u $11 \&$ d o c i d = B 5917 D E 7 D 3FE1B1D8325713700735B41

Instituto Brasileiro de Opinião Pública e Estatística. (2006b).

$O$ que esperar da internet nos próximos anos? Recuperado em 15 abril, 2006, de http://www.ibope. com.br/calandraWeb/servlet/ CalandraRedirect? te $\mathrm{mp}=6 \&$ proj $=$ PortalIBOPE $\&$ pub $=T \& d b=$ caldb\&comp=pesquisa_leitura\& nivel=null $\&$ docid $=6323184$ D 74 80D850832570F40048C417
Jaruwachirathanakul, B., \&

Fink, D. (2005).

Internet banking adoption strategies for a developing country: the case of Thailand. Internet Research, 15(3), 295-311.

Joreskög, K. G. (1993).

Testing structural equation models. In K. Bollen \& J. S. Long (Eds.). Testing Structural Equation Models. Newbury Park, CA: Sage Publications.

Karahanna, E., \&

Straub, D. W. (1999).

The psychological origins of perceived usefulness and ease-ofuse. Information and Management, 35(4), 237-250.

Lee, E. J.,

Kwon, K. N., \&

Schumann, D. W. (2005).

Segmenting the non-adopter category in the diffusion of internet banking. The International Journal of Bank Marketing, 23(4-5), 414-437.

Liao, S.,

Shao, Y. P.,

Wang, H., \&

Chen, A. (1999).

The adoption of virtual banking: an empirical study. International Journal of Information Management, 19(1), 63-74.

Liao, Z., \&

Chewung, M. T. (2002).

Internet-based e-banking and consumer attitudes: an empirical study. Information \& Management, 39(4), 283-298. 
Lieberman, Y., \&

Stashevsky, S. (2002).

Perceived risks as barriers to internet and e-commerce usage. Qualitative Market Research, 5(4), 291-300.

Malhotra, N. (1999).

Marketing research: an applied orientation (3rd ed.). New York: Prentice Hall, Inc.

Moore, G. C., \&

Benbasat, I. (1991).

Development of an instrument to measure the perceptions of adopting an information technology information. Information Systems Research, 2(3), 173-191.

Müller, F. R. (2001).

Identificação das causas da não utilização do sistema de internet banking da Caixa Econômica Federal em Porto Alegre. Dissertação de mestrado. Universidade Federal de Porto Alegre, Porto Alegre, RS, Brasil.

Ndubisi, N. O., \&

Sinti, Q. (2006).

Consumer attitudes, system's characteristics and internet banking adoption in Malaysia. Management Research News, 29(1-2), 16-27.

Nunnally, J. C. (1978).

Psychometric theory (2nd ed.). New York: McGraw-Hill.

Rogers, E. M. (1983).

Diffusion of innovations. The Free Press: New York.
Sathye, M. (1999).

Adoption of internet banking by Australian consumers: an empirical investigation. The International Journal of Bank Marketing, 17(7), 324-333.

Shih, Y. Y., \&

Fang, K. (2004).

The use of a decomposed theory of planned behavior to study internet banking in Taiwan. Internet Research, 14(3), 213-223.

Shih, Y. Y., \&

Fang, K. (2006).

Effects of network quality attributes on customer adoption intentions of internet banking. Total Quality Management \& Business Excellence, 17(1), 61-69.

Suh, B., \&

Han, I. (2002).

Effect of trust on customer acceptance of internet banking. Electronic Commerce Research \& Applications, 1(3), 247-263.

Suh, B., \&

Han, I. (2003).

The impact of customer trust and perception of security control on the acceptance of electronic commerce. International Journal of Electronic Commerce, 7(3), 135-161.

Tan, M., \&

Teo, T. S. (2000).

Factors influencing the adoption of internet banking. Journal of the Association for Information Systems, 1(1), Artigo 5. 
Taylor, S., \&

Todd, P. A. (1995). Understanding information technology usage: a test of competing models. Information Systems Research, 6(2), 144-176.

Tero, P.,

Kari, P.,

Karjaluoto, H., \&

Pahnila, S. (2004).

Consumer acceptance of online banking: an extension of the technology acceptance model. Internet Research, 14(3), 224-235.

Tornatzky, L. G., \&

Klein, K. J. (1982).

Innovation characteristics and innovation adoption-implementation: a meta-analysis of findings. IEEE Transactions on Engineering Management, 29(1), 28-45.
Venkatesh, V., \&

Davis, F. D. (2000).

A theoretical extension of the technology acceptance model: four longitudinal field studies. Management Science, 45(2), 186-204.

Venkatesh, V.,

Morris, M. G.,

Davis, G. B., \&

Davis, F. D. (2003).

User acceptance of information technology: toward a unified view. MIS Quarterly, 27(2), 425-478.

Wang, Y.,

Wang, Y.,

Lin, H., \&

Tang, T. (2003).

Determinants of user acceptance of internet banking: an empirical study. International Journal of Service Industry Management, 14(5), 501-520. 


\section{ANEXO 1}

\section{Itens dos Constructos}

\begin{tabular}{|c|c|c|c|}
\hline Constructo & Item & $\begin{array}{c}\text { Carga } \\
\text { Fatorial }\end{array}$ & Alpha \\
\hline \multirow{4}{*}{$\begin{array}{l}\text { Vantagem Relativa } \\
\text { de Conveniência }\end{array}$} & O IB é melhor porque ele está disponível 24 horas por dia em todos os dias do ano & 0,82 & \multirow{4}{*}{0,93} \\
\hline & $\begin{array}{l}\text { O IB é melhor porque me permite fazer transações com o Banco de qualquer lugar } \\
\text { do mundo }\end{array}$ & 0,91 & \\
\hline & O IB é melhor porque seria mais rápido fazer transações & 0,89 & \\
\hline & O IB é melhor porque eu economizaria tempo ao fazer minhas transações & 0,86 & \\
\hline \multirow{3}{*}{$\begin{array}{c}\text { Vantagem Relativa } \\
\text { de Segurança e } \\
\text { Privacidade }\end{array}$} & $\begin{array}{l}\text { O IB é melhor porque seria menos provável que ladrões pudessem fazer transações } \\
\text { em meu nome }\end{array}$ & 0,83 & \multirow{3}{*}{0,86} \\
\hline & $\begin{array}{l}\text { O IB é melhor porque seria menos provável que alguém roubasse as informações } \\
\text { que tenho no Banco }\end{array}$ & 0,82 & \\
\hline & $\begin{array}{l}\text { O IB é melhor porque seria menos provável que o Banco vendesse minhas } \\
\text { informações }\end{array}$ & 0,79 & \\
\hline \multirow{3}{*}{$\begin{array}{l}\text { Vantagem Relativa } \\
\text { de Controle }\end{array}$} & O IB é melhor porque me daria mais controle sobre minhas finanças pessoais & 0,81 & \multirow{3}{*}{0,91} \\
\hline & O IB é melhor porque permitiria programar melhor os pagamentos de contas & 0,82 & \\
\hline & $\begin{array}{l}\text { O IB é melhor porque seria mais fácil recuperar informações sobre as transações } \\
\text { mais antigas }\end{array}$ & 0,76 & \\
\hline \multirow{3}{*}{ Visibilidade } & Eu já vi como as pessoas usam o IB & 0,87 & \multirow{3}{*}{0,92} \\
\hline & É comum ver outras pessoas usando o IB & 0,85 & \\
\hline & Eu já vi quais as transações que as pessoas costumam fazer pelo IB & 0,83 & \\
\hline \multirow{4}{*}{$\begin{array}{l}\text { Demonstrabilidade } \\
\text { de Resultados }\end{array}$} & $\begin{array}{l}\text { Eu me sentiria à vontade para explicar aos meus amigos quais os benefícios de usar } \\
\text { o IB }\end{array}$ & 0,79 & \multirow{4}{*}{0,93} \\
\hline & Eu saberia dizer para os meus amigos as vantagens e desvantagens de usar o IB & 0,87 & \\
\hline & Os benefícios de usar o IB são claros para mim & 0,78 & \\
\hline & Eu não teria nenhuma dificuldade em explicar em que o IB é bom ou não & 0,82 & \\
\hline \multirow{3}{*}{$\begin{array}{l}\text { Compatibilidade } \\
\text { com Estilo de Vida }\end{array}$} & O IB é compatível com meu estilo de vida & 0,77 & \multirow{3}{*}{0,93} \\
\hline & Usar o IB adaptar-se-ia muito bem ao meu jeito de administrar minhas finanças & 0,82 & \\
\hline & $\begin{array}{l}\text { Usar o IB para fazer transações bancárias adaptar-se-ia bem às minhas } \\
\text { características pessoais }\end{array}$ & 0,82 & \\
\hline Facilidade de Usar & O IB exigiria um grande esforço mental para ser utilizado & 0,96 & \\
\hline \multirow{3}{*}{ Testagem } & O banco proporcionou oportunidades para eu testar o IB & 0,88 & \multirow{3}{*}{0,88} \\
\hline & O banco deixou disponível para mim o IB para que eu pudesse fazer testes & 0,91 & \\
\hline & $\begin{array}{l}\text { O banco ofereceu treinamento ou informações adequadas para que eu pudesse usar o } \\
\text { IB }\end{array}$ & 0,84 & \\
\hline \multirow{3}{*}{ Imagem } & Usar IB melhoraria a minha imagem & 0,82 & \multirow{3}{*}{0,86} \\
\hline & As pessoas que usam IB têm mais prestígio que aquelas que não usam & 0,86 & \\
\hline & Usar IB é um símbolo de status & 0,85 & \\
\hline \multirow{3}{*}{ Normas Subjetivas } & Meus amigos influenciam a minha decisão de usar o IB & 0,89 & \multirow{3}{*}{0,92} \\
\hline & Minha família influencia a minha decisão de usar IB & 0,88 & \\
\hline & Meus colegas de trabalho ou de escola influenciam minha decisão de usar IB & 0,92 & \\
\hline \multirow{4}{*}{ Auto-Eficácia } & Mesmo apenas com as instruções online eu teria confiança de usar o IB & 0,79 & \multirow{4}{*}{0,95} \\
\hline & Mesmo que não tenha ninguém para me orientar, eu teria confiança de usar o IB & 0,86 & \\
\hline & Mesmo que eu nunca tivesse utilizado o IB, eu teria confiança em usá-lo & 0,89 & \\
\hline & $\begin{array}{l}\text { Independentemente de eu ter visto outras pessoas usando o IB, eu teria confiança de } \\
\text { usá-lo }\end{array}$ & 0,86 & \\
\hline $\begin{array}{c}\text { Suporte } \\
\text { Tecnológico }\end{array}$ & A tecnologia da Internet torna o IB fácil de ser usado & 0,88 & \\
\hline $\begin{array}{c}\text { Suporte } \\
\text { Governamental }\end{array}$ & O governo estimula as pessoas a usar a Internet & 0,96 & \\
\hline
\end{tabular}

